\title{
Strengthening rural health placements for medical students: Lessons for South Africa from international experience
}

\author{
J E Doherty, BVSc, MPhil, DHSM; I Couper, BA, MB BCh, MFamMed, FCFP (SA) \\ Centre for Rural Health, Faculty of Health Sciences, University of the Witwatersrand, Johannesburg, South Africa
}

Corresponding author: J E Doherty (dohertyj@telkomsa.net)

\begin{abstract}
Background. This article derives lessons from international experience of innovative rural health placements for medical students. It provides pointers for strengthening South African undergraduate rural health programmes in support of the government's rural health, primary healthcare and National Health Insurance strategies.

Methods. The article draws on a review of the literature on 39 training programmes around the world, and the experiential knowledge of 28 local and international experts consulted through a structured workshop.

Results. There is a range of models for rural health placements: some offer only limited exposure to rural settings, while others offer immersion experiences to students. Factors facilitating successful rural health placements include faculty champions who drive rural programmes and persuade faculties to embrace a rural mission, preferential selection of students with a rural background, positioning rural placements within a broader rural curriculum, creating rural training centres, the active nurturing of rural service staff, assigning students to mentors, the involvement of communities, and adapting rural programmes to the local context. Common obstacles include difficulties with student selection, negative social attitudes towards rural health, shortages of teaching staff, a sense of isolation experienced by rural students and staff, and difficulties with programme evaluation.

Conclusions. Faculties seeking to expand rural placements should locate their vision within new health system developments, start off small and create voluntary rural tracks, apply preferential admission for rural students, set up a rural training centre, find practical ways of working with communities, and evaluate the educational and clinical achievements of rural health placements.
\end{abstract}

S Afr Med J 2016;106(5):524-527. DOI:10.7196/SAMJ.2016.v106i5.10216

South Africa (SA) faces a shortage of doctors, especially in the public sector and in rural areas. ${ }^{[1]}$ This poses a challenge to implementing many of the government's health policies, including National Health Insurance, and undermines equity.

Not only must more doctors be trained, but new training models are required that will motivate graduates to serve in rural and remote areas and equip them to do so. ${ }^{[2]}$ Doctors must be responsive to the needs of rural communities and able to function in poorly resourced contexts, while meeting the ethical and clinical standards of their urban counterparts. Health sciences faculties must become more accountable to the communities they serve. ${ }^{[3]}$

SA faculties have some form of rural placement for medical students, but in the majority of cases these rotations are of short duration and separate from core clinical disciplines. The main exception is Walter Sisulu University, where for many years the Faculty of Health Sciences has offered a community-based programme in a largely rural context, and medical students are now placed for 6-month periods in rural hospitals. Another significant innovation is the Ukwanda Rural Clinical School at Stellenbosch University. This places small groups of health professionals at a regional site and in smaller rural towns; in the case of medical students, this is for $6-18$ months.

Despite these innovations, exposure to rural training for the majority of SA students is limited and only a small fraction of graduates end up working in rural areas in the longer term. ${ }^{[4]}$ Furthermore, there is no government policy that incentivises rural training.

This article draws out lessons from the international experience of innovative rural health placements for undergraduate health professionals. The objective is to provide pointers for strengthening existing - and designing new - rural health programmes in SA.

\section{Methods}

This article draws first on a 2011 review of the international literature on rural medical training ${ }^{[5]}$ and the proceedings of a subsequent conference in 2012. The literature review searched PubMed, Google Scholar and faculty of health sciences websites to identify peerreviewed and 'grey' literature. Search terms used were 'rural training' and 'rural undergraduate training' (in combination with 'health professionals'), as well as 'rural medical education'.

Articles or reports were included in the review if they reported on the implementation of a rural educational programme for students in the health professions. No limitations were placed on the length of rural placements, and the definition of 'rural' used by each programme was accepted. Reference lists of identified articles were scanned to find additional literature. Review articles were prioritised. In the end 88 documents were reviewed, although this article only references a few of these (the full review is available at https:// healthpolicysa.files.wordpress.com/2011/02/alternative-models-forrural-training_finall.pdf).

The majority of the 39 programmes identified by the review had been evaluated favourably with regard to their impact on student performance and rural retention of doctors, although some more recent programmes had not yet undergone evaluation. The majority of the programmes described were in Australia and North America, which have had several decades of experience. Other areas - such as Central and South-East Asia, and Latin America - are known to have had considerably more experience than the review was able to tap because of language barriers, or because not all successful programmes have been able to publish in internationally accessible media.

These limitations were mitigated to some extent by triangulating data from different sources, getting feedback on the review from two 
international experts and, for this article, incorporating the findings of a conference for which the initial literature review was drafted. Twenty-four SA academics and senior health managers, and four Australian and Canadian experts, attended the conference, which focused on the development of rural clinical academic leadership. A series of smallgroup discussions with feedback to plenary sessions led to the development of consensus recommendations. These represented the combined experiential or 'tacit' knowledge of experts steeped in the development of rural services and rural training programmes internationally and at home. This guidance is invaluable in a terrain that has hitherto been poorly documented and researched.

\section{Results \\ Different models for rural placements}

Internationally, as revealed by the review, successful rural placements share some common features. They reorient training towards primary care and family medicine, integrate clinical and public health concerns, use problem-solving and community-based teaching methods, and adapt courses to the local context. Key to achieving high standards is the integration of different subdisciplines and longitudinal exposure of students to communities. There is emerging interest in interprofessional training.

Beyond this broad educational approach, there are differences in the way rural placements are designed. Models for rural placements fall along a continuum of intensity of exposure to rural settings (Table 1). The least intensive end of the continuum, which typifies the historical training model of most health sciences faculties in SA, involves a rural placement that takes place towards the end of the course, is very short (only a few weeks) and does not involve rural mentors. The most intensive end of the continuum, typified by programmes such as those at the Northern Ontario School of Medicine in Canada, James Cook University in Australia and
Ateneo de Zamboanga School of Medicine in the Philippines, involves introducing students early and frequently to rural environments, a main rural placement that is long (6 months or more), and attaching students to mentors. Students often join a dedicated rural track at the start of their degree, and may spend much of their course at a rural campus. In many cases, the clinical school itself is based in a small regional centre or rural area.

It is these more intensive programmes that are thought to result in a larger proportion of students choosing a future career in rural practice ${ }^{[6]}$ By becoming immersed in the issues faced in rural settings, students learn about the realities and satisfaction of rural practice. Longer placements allow students to develop a rural home base, become fully participating members of the healthcare team and interact socially with the community. More generally, rural training provides students with access to more patients and a wider range of cases, giving them hands-on experience and greater levels of clinical responsibility, allowing holistic interaction with the patient, family and community, and exposing them to integrated primary healthcare.

\section{Factors affecting the effectiveness and sustainability of rural placements}

Most international rural programmes have been motivated by, and draw legitimacy from, national or state policies that seek to address human resource shortages, expand access to healthcare in rural areas or strengthen primary healthcare. Many programmes exist because they have received targeted government funding. In Australia, for example, 4 - 6-week rural clinical placements were initially made compulsory for all students. In 2001 an undergraduate rural health strategy saw the creation of 14 rural clinical schools, at which a minimum of a quarter of the students spend at least half their clinical training time. ${ }^{[7,8]}$

Rural training programmes are most effective when they form part of a 'pipeline'

\section{Table 1. Extremes of the continuum of rural exposure during training ${ }^{[5]}$}

\begin{tabular}{ll}
\hline Most intense exposure & Least intense exposure \\
\hline Students are introduced early to rural environments & $\begin{array}{l}\text { Rural placement happens towards the } \\
\text { end of the programme } \\
\text { There is only one rural placement }\end{array}$ \\
$\begin{array}{l}\text { Rural placements occur at periodic moments } \\
\text { throughout the programme }\end{array}$ & $\begin{array}{l}\text { The main rural placement is long (6 months or more) } \\
\text { Students are attached to individual health } \\
\text { professionals who act as mentors }\end{array}$
\end{tabular}

for rural health professional development. The term 'pipeline' refers to the practice of making sure that there is a continuous supply of motivated, skilled students who are recruited effectively and then pass steadily through a range of training opportunities that progressively enhance their ability to practise effectively in rural areas. Strategies include encouraging rural high-school students to apply for health professional training, supporting them during their undergraduate degrees, providing postgraduate and continuing education opportunities, and developing appropriate recruitment and retention strategies for rural areas. ${ }^{[9]}$ Thailand's comprehensive strategy for strengthening rural health services includes, for example, the training of rural health professionals through local recruitment and highly subsidised training and living expenses for students, followed by binding contracts for post-graduation work in rural areas for a number of years. ${ }^{[10]}$

Champions within faculties are required to drive the development of rural health placements, especially where there is some resistance to the concept of rural training. For example, in Venezuela, initiating and maintaining a rural training programme depended on the sustained hard work of highly committed academics who drove the rural training agenda in their faculty. ${ }^{[11]}$

Further, rural training programmes are complex and time-consuming: this derives from the networking required with rural health facilities, practitioners and communities, the need to train trainers who are based in the health service, and the logistics associated with placing students in communities. Rural programmes therefore find it easier to thrive in faculties that see rural training as part of their mission and provide resources and other support for these efforts. A strong reason for faculties to support rural training is growing pressure to demonstrate social accountability. ${ }^{[3]}$

The literature is not very clear on how training is best co-ordinated in rural sites where faculties are based in large towns or metropolitan areas, or on whether a rural campus or training centre needs to be set up in all these cases. Rural clinical schools are an established feature in Australia, whereas in the USA there are 63 rural campuses, but only four of these are in towns with less than about 20000 people. ${ }^{[8]}$ However, rural training centres offer the benefits of co-ordination of training for different types of health professional at different levels (undergraduate, postgraduate, continuing education, etc.), allowing students to meet for formal teaching, providing accommodation 
for students and building a teaching culture in a rural setting that will contribute towards long-term recruitment and retention of both students and service-based teaching staff.

Providing support to health professionals at teaching sites, and encouraging collegial interaction between rural and urban teaching staff, are noted as critical to the sustainability of a training programme. $^{[12]}$ Local staff represent a key resource with regard to improving the quality of care, providing clinical governance, protecting patient safety and contributing to the social accountability of health services and universities. As even well-established programmes often depend on a few key individuals, rural trainers need to be nurtured: the provision of training for trainers, the creation of joint positions with universities, administrative support and inclusion in rural research efforts are strategies mentioned in the literature.

Preferential selection of students from rural backgrounds is one of the most significant predictors of choice of rural location for future practice. ${ }^{[13]}$ Consequently, most international programmes select at least a portion of the student body on this basis. Academic and social support may also be required, especially in the early years, to compensate for weaknesses in secondary education in rural areas and help students make the transition from their rural places of origin to urban university campuses. Financial concerns are a critical problem, and student selection often has to go hand in hand with scholarship programmes to make health sciences training financially viable for these students.

During their rural placement, students in successful programmes are assigned to an on-site supervisor (often referred to in the international literature as a 'preceptor'). This is a health professional who becomes a personal mentor throughout the student's stay: this person provides personal support to the student, acts as a role model, and may be responsible for training in communication and clinical skills. Students particularly benefit from this when they are assigned to a health professional working in their community of origin. In many of the North American programmes, the preceptor may be a primary care physician in private practice, or work at a state facility.

Without the active involvement of rural communities it is difficult to recruit students who are committed to rural practice, set up sustainable and educationally appropriate rural placements, and make rural placements enjoyable. The integral involvement of communities makes quite ambitious rural placements feasible.

\section{Challenges faced by rural programmes}

The literature makes frequent mention of how students' commitment to rural practice is undermined by negative social attitudes on the part of some faculty staff towards generalist and rural practice: these are sometimes regarded as 'second-best' training and career options. New programmes that embrace rural training methods are not easily accepted and can find it difficult to stick to their founding vision in the face of more traditional norms. It is also difficult to assimilate new teaching approaches into traditional curricula.

Because the mother faculty is often located in an urban setting, and training through the rest of the curriculum tends to occur in high-level academic hospitals, rural students are often anxious that students at these sites will receive superior training.

Perversely, rural placement experiences can in fact drive students away from rural practice, particularly if the placement is poorly organised and there is poor clinical and personal support. In Tanzania, for example, students who had a community health rotation during their training were less likely to accept a job in a rural area than other students. ${ }^{[14]}$ Limited funding and logistical difficulties in remote areas are part of the problem. This is because healthcare facilities are often of poor quality, supplies of equipment are erratic, housing is poor, and there are limited teaching resources such as educational infrastructure, teaching aids, libraries and internet access.

Apart from the challenges of clinical practice in remote settings, including limited professional support, students experience personal problems such as a sense of isolation from family and friends, difficulties integrating into the new community, a lack of privacy, little entertainment and few opportunities for their partners. This may deter students from enrolling for rural placements and be a more important factor than educational issues in a student's choice.

Apart from compromising the apprenticeship model on which most rural placements are based, staff shortages can lead to the perception that students aggravate workloads and slow down consultations and procedures. However, a study from Australia found that this perception is not necessarily accurate, and that the reverse may well be true, ${ }^{[15]}$ while in the Philippines it was found that health services appreciate the presence of students for a number of reasons, including the assistance they provide in dealing with heavy workloads (I Couper, study tour report on visit to the Philippines,15 February - 1 March 2011, unpublished).

Finally, setting up rural training programmes is certainly costly. ${ }^{[16]}$ A noteworthy gap in the literature is comparison of the costs of training health professionals through conventional v. intensive rural training programmes. A chapter in the recently published international Rural Medical Education Guidebook highlights some of the complexities and challenges that need to be considered in looking at this issue. ${ }^{[17]}$ It should be noted that the Northern Ontario School of Medicine has demonstrated that its distributed rural medical education programme has had a substantial positive socioeconomic impact on local communities. ${ }^{[18]}$

\section{Implications for SA}

The international literature reveals the complexity and intensity of successful rural programmes. This suggests that SA faculties of health sciences seeking to expand rural placements should 'start small'. Many international rural programmes began with very few students (typically less than 10), and some still only produce limited numbers of students annually. Furthermore, most programmes internationally rely on voluntary enrolment, the exceptions being those offered by faculties that have a specifically rural mission. It seems advisable to use the approach of a rural track, as it allows scarce resources to be focused more directly on students who have a particular interest in rural practice and makes logistics more manageable.

It is clearly important to recruit some students on the basis of their rural background, involving communities in the selection process where possible in order to 'bond' students to returning to their place of origin, either through formal contracts entered into at the point of admission or through informal, emotional links between students and their communities. Selective admission should be accompanied by other curricular activities that specifically support rural students and attract other students who have a rural interest.

Dedicated rural training sites and facilities are necessary to achieve more than superficial exposure for students to rural settings and to foster interprofessional training. Rural training centres are also a mechanism for supporting local health professionals, who are essential to sustainable training in the rural setting.

Programmes need to ensure that students have a positive experience of the clinical aspects of the rural attachment, the assigned rural mentor and integration into the community. The literature notes that providing good accommodation is a priority, including adequate teaching spaces. Free accommodation and reimbursement of travel costs incentivise students to embark on rural placements and 
mitigate the impact on students' financial wellbeing. Other amenities that make a rural placement more pleasant are group tutorials and internet access.

The literature also notes that it is important to demonstrate that, although students at rural and urban sites have different clinical experiences, the learning outcomes can be the same, provided there are high educational and clinical standards. In fact, individualising learning processes, while focusing on common competencybased outcomes, is central to the notion of transformative medical education. ${ }^{[19]}$ However, it is important to select rural sites carefully, matching local epidemiology with curricular goals and also assessing the capacity of local health professionals to create a sustainable teaching programme. Sites need to be monitored carefully and discontinued should they not provide adequate training experiences. However, assessment measures should also capture the unique advantages of rural settings.

Finally, new government policies in SA - on a rural health strategy, re-engineered primary healthcare, strengthening rural health services and even National Health Insurance - provide opportunities for SA health sciences faculties to locate new developments in rural training within these efforts, and demonstrate social accountability.

\section{Conclusions}

There are two main outcomes from rural training: the provision of good-quality educational and clinical opportunities, and the recruitment of doctors to rural practice. To achieve the latter, it appears that the scale of a rural training programme needs to be considerably enlarged (at least 3 months or longer, although the international research is not yet sufficiently robust to provide conclusive advice in this regard). To achieve the former, it may be sufficient to supplement rural sites with urban or periurban sites in disadvantaged areas, with a focus on primary care, but it is the way that training happens in these sites that will determine their value. In SA, the short-term costs associated with expanding rural training will undoubtedly constrain the choice. It must be remembered in making this choice, however, that there is the potential for positive socioeconomic impacts on rural communities arising from decentralised training. At the same time, there are long-term societal costs associated with conventional training programmes that produce health professionals ill-suited or unwilling to serve rural and disadvantaged populations.

Setting up a training programme that offers expanded rural experience is complex. It includes developing a tailor-made rural programme and integrating it into the wider curriculum, identifying collaborating teaching hospitals, clinics and communities as well as preceptors, partnering with community-based organisations, and working closely with different levels of government. Health systems develop and expand unevenly, while communities' and patients' demands grow, especially when integrally involved in rural training. Rural programmes therefore need to operate within a context of change and uncertainty. This in turn requires strong commitment and leadership on the part of faculties of health sciences, and strong policy and associated funding from government.

Funding source. This article is based on work commissioned by the Faculty of Health Sciences, University of the Witwatersrand, SA, some of which was in partnership with Monash University, Australia.

\section{References}

1. National Department of Health, South Africa. Human Resources for Health, South Africa. HRH Strategy for the Health Sector: 2012/13-2016/17. Pretoria: NDoH, 2011. http://www.gov.za/ documents/human-resources-health-south-africa-hrh-strategy-health-sector-201213-201617 accessed 28 November 2015)

2. World Health Organization. Increasing Access to Health Workers in Remote and Rural Areas Through Improved Retention: Global Policy Recommendations. Geneva: WHO, 2010. http://www.searo.who. int/nepal/mediacentre/2010_increasing_access_to_health_workers_in_remote_and_rural_areas.pdf (accessed 28 November 2015).

3. Global consensus for social accountability of medical schools. 2010. http://healthsocialaccountability. org (accessed 28 November 2015)

Tomlinson C. Doctors and the human resources crisis. Equal Treatment 2009; Issue 29 (Sept):2-6. http:// www.tac.org.za/community/files/file/etmag/ET29/ET29English.pdf (accessed 28 November 2015).

5. Doherty J. Models for undergraduate rural health placements. In: Chater AB, Rourke J, Couper I, Doherty J. Models for undergraduate rural health placements. In: Chater AB, Rourke J, Couper I, Strasser R, Reid S, eds. Rural Medical Education Guidebook. World Organization of Family Doctors (WONCA) Working Party on Rural Practice, 2014:ch. 4.3.1. http://WWw.globalfam
groups/WorkingParties/RuralPractice/ruralguidebook.aspx (accessed 22 March 2016).

groups/WorkingParties/RuralPractice/ruralguidebook. aspx (accessed 22 March 2016).
6. Eley D, Young L, Wilkinson D, Chater A, Bakerilkinson P. Coping with increasing numbers of medical 6. Eley D, Young L, Wilkinson D, Chater A, Bakerilkinson P. Coping with increasing numbers of medist
students in rural clinical schools: Options and opportunities. Med J Aust 2008;188(11):669-671. students in rural clinical schools: Options and opportunities. Med J Aust 2008;188(11):669-671.
7. Tesson G, Curran V, Pong R, Strasser R. Advances in rural medical education in three countries: . Tesson G, Curran V, Pong R, Strasser R. Advances in rural medical
Canada, the United States and Australia. Educ Health 2005;18(3):405-415.

8. Crump WJ, Barnett D, Fricker S. A sense of place: Rural training at a regional medical school campus. J Rural Health 2004;20(1):80-84. DOI:10.1111/j.1748-0361.2004.tb00011

9. Norris TE. Education for rural practice: A saga of pipelines and plumbers. J Rural Health 2008;16(3):208-212. DOI:10.1111/j.1748-0361.2000.tb00458.x

10. Wibulpolprasert S, Pengpaibon P. Integrated strategies to tackle the inequitable distribution of doctors in Thailand: Four decades of experience. Hum Resour Health 2003;1(1):12. DOI:10.1186/1478-44911-12

11. Borroto Cruz E, Salas Perea R. National training program for comprehensive community physicians, Venezuela. MEDICC Rev 2008;10(4):35-42. Doherty J, Couper I, Campbell D, Walker J. Transforming rural health systems through clinical academic leadership: Lessons from South Africa. Rural Remote Health 2013;13(2618).

12. Wilson NW, Couper ID, de Vries E, Reid S, Fish T, Marais BJ. A critical review of interventions to redress the inequitable distribution of healthcare professionals to rural and remote areas. Rural Remote Health 2009;9(1060)

13. Leon B, Kolstad J. Wrong schools or wrong students? The potential role of medical education in regional imbalances of the health workforce in the United Republic of Tanzania. Hum Resour Health 2010;8(3). DOI:10.1186/1478-4491-8-3

14. Walters L, Worley P, Prideaux D, Lange K. Do consultations in rural general practice take more time when practitioners are precepting medical students? Med Educ 2008;42(1):69-73. DOI:10.1111/j.13652923.2007.02949.x

15. Walsh K. Comment: Cost and returns related to medical education in rural and remote locations. Rural Remote Health 2013;13(2):2584.

16. Jong M. Health systems and funding of rural-based medical education. In: Chater AB, Rourke J, Couper I, Strasser R, Reid S, eds. Rural Medical Education Guidebook. World Organization of Family Doctors (WONCA) Working Party on Rural Practice, 2014:ch. 1.2.1. http://www.globalfamilydoctor. Doctors (WONCA) Working Party on Rural Practice, 2014:ch. 1.2.1. http://www.globalfamil
com/groups/WorkingParties/RuralPractice/ruralguidebook.aspx (accessed 22 March 2016).

com/groups/WorkingParties/RuralPractice/ruralguidebook.aspx (accessed 22 March 2016).
17. Strasser R, Hogenbirk JC, Minore B, et al. Transforming health professional education through Strasser R, Hogenbirk JC, Minore B, et al. Transforming health professional education through
social accountability: Canada's Northern Ontario School of Medicine. Med Teach 2013;35(6):490social accountability: Canada's Northern O

18. Frenk J, Chen L, Bhutta Z, et al. Health professionals for a new century: Transforming education to strengthen health systems in an interdependent world. Lancet 2010;376(9756):1923-1958. DOI:10.1016/S0140-6736(10)61854-5

Accepted 4 March 2016. 